\title{
The incidence, success rate, and complications of awake tracheal intubation in 1,554 patients over 12 years: an historical cohort study
}

\section{Incidence, taux de réussite et complications de l'intubation trachéale chez 1554 patients éveillés sur une période de 12 ans: une étude de cohorte historique}

\author{
J. Adam Law, MD • Ian R. Morris, MD • Paul A. Brousseau, BEd • Sylvia de la Ronde, MSc • \\ Andrew D. Milne, MD
}

Received: 20 October 2014/Accepted: 7 April 2015/Published online: 24 April 2015

(c) Canadian Anesthesiologists' Society 2015

\begin{abstract}
Purpose Awake tracheal intubation is one recommended option to address select situations in the management of a patient with an anticipated difficult airway. A scarcity of data exists on how often awake intubation is performed or whether its use is changing over time, particularly with the increasingly widespread availability of video laryngoscopy. This retrospective database review was undertaken to determine the incidence, success, and complications of awake intubation and the incidence of other tracheal intubation techniques in the operating room over a 12-yr period (2002-2013) at our institution.

Methods The Anesthesia Information Management System in use at a Canadian tertiary care centre was searched for all awake intubations that occurred during the years 2002-2013. Records were also searched to identify
\end{abstract}

This article is accompanied by an editorial. Please see Can J Anesth 2015; 62: this issue.

Author contributions J. Adam Law conceived the study and Andrew D. Milne was involved with the study design. J. Adam Law and Andrew D. Milne participated in the data analysis. J. Adam Law, Andrew D. Milne, and Ian R. Morris contributed to data

interpretation. J. Adam Law wrote the manuscript. J. Adam Law, Ian R. Morris, Paul A. Brousseau, Sylvia de la Ronde, and Andrew D. Milne contributed to critical revisions of the article. Paul A. Brousseau retrieved the data from the database. Sylvia de la Ronde performed the statistical analysis.

J. A. Law, MD $(\square)$. I. R. Morris, MD

P. A. Brousseau, BEd · S. de la Ronde, MSc · A. D. Milne, MD Department of Anesthesia, Dalhousie University, QEII Health Sciences Centre, Halifax, Infirmary Site, 1796 Summer Street, Halifax, NS B3H 3K9, Canada

e-mail: jlaw@dal.ca airway methods other than direct laryngoscopy that may have been used after the induction of general anesthesia. Changes in both the incidence of awake intubation and in the use of video laryngoscopy over the 12 years were analyzed using linear regression modelling.

Results Of 146,252 cases performed under general anesthesia with endotracheal intubation, 1,554 intubations $(1.06 \%)$ were performed awake. There was no significant change in the rate of awake intubation over the studied years (slope $-1.4^{-4}$ incidence $\cdot y e a r^{-1} ; 95 \%$ confidence interval [CI]: $-3.0^{-4}$ to $3.0^{-5} ; P=0.102$ ). The relatively steady rate of awake intubation occurred despite a significant increase in the use of video laryngoscopy over the same time

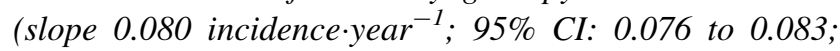
$P<0.001)$, particularly from 2009 onwards. Attempted awake intubation failed in 31 (2\%) of the cases. Self-reported complications occurred in $15.7 \%$ of successful procedures. In addition, in a convenience sample of three years (20112013), the rate at which each of 49 attending staff performed awake intubation varied widely from 0-3.4 awake intubations per 100 cases of general anesthesia with endotracheal intubation.

Conclusions At our tertiary care centre, we did not find a significant change in the use of awake tracheal intubation over the studied years 2002-2013 despite increasing availability and use of video laryngoscopy. It appears that awake tracheal intubation retains an important and consistent role in the management of the difficult airway.

\section{Résumé}

Objectif L'intubation trachéale du patient éveillé, qu'on appelle aussi intubation vigile, est une alternative recommandée dans certaines situations précises pour 
prendre en charge un patient présentant des voies aériennes anticipées comme étant difficiles. Il n'existe que très peu de données concernant la fréquence à laquelle on réalise une intubation vigile ou si son utilisation change au fil du temps, particulièrement au vu de la disponibilité de plus en plus répandue de la vidéolaryngoscopie. Cette revue rétrospective de base de données a été entreprise afin de déterminer l'incidence, le taux de réussite et les complications liées à l'intubation chez le patient éveillé ainsi que l'incidence d'autres techniques d'intubation trachéale en salle d'opération au cours d'une période de 12 ans (2002-2013) dans notre centre.

Méthode Le système de gestion de l'information en anesthésie utilisé dans un centre de soins tertiaires canadien a été analysé pour en tirer tous les cas d'intubations vigiles survenus entre 2002 et 2013. On a également étudié les dossiers pour déterminer les méthodes de prise en charge des voies aériennes autres que la laryngoscopie directe qui pourraient avoir été utilisées après l'induction de l'anesthésie générale. Les changements dans l'incidence d'intubations vigiles et l'utilisation de la vidéolaryngoscopie au cours de ces 12 ans ont été analysés à l'aide d'un modèle de régression linéaire.

Résultats Sur les 146252 cas réalisés sous anesthésie générale avec intubation endotrachéale, 1554 intubations $(1,06 \%)$ ont été réalisées chez un patient éveillé. Aucun changement significatif du taux d'intubations vigiles n'a été observé au cours de la période à l'étude (pente $-1,4^{-4}$ incidence année ${ }^{-1}$; intervalle de confiance [IC] $95 \%:-3,0^{-4}$ à $3,0^{-5} ; P=0,102$ ). Le taux relativement stable d'intubations vigiles peut être observé malgré l'augmentation significative de l'utilisation de vidéolaryngoscopie au cours de la même période (incidence 0,080 incidence année ${ }^{-1}$; IC $95 \%$ : 0,076 à 0,$083 ; P<0,001)$, particulièrement à partir de 2009. Les tentatives d'intubation vigile ont échoué dans 31 (2 \%) cas. Des complications autorapportées sont survenues dans $15,7 \%$ des interventions réussies. En outre, dans un échantillon de commodité de trois ans (2011-2013), le taux auquel chacun des 49 patrons a réalisé des intubations vigiles a grandement varié, allant de 0 à 3,4 intubations par 100 cas d'anesthésie générale avec intubation endotrachéale.

Conclusion Dans notre centre de soins tertiaires, nous n'avons pas trouvé de changement significatif dans l'utilisation de l'intubation trachéale vigile au cours de la période étudiée (2002-2013), malgré la disponibilité et l'utilisation croissantes de la vidéolaryngoscopie. Il semble que l'intubation trachéale vigile garde un rôle important et constant dans la prise en charge de voies aériennes difficiles.
Awake tracheal intubation can be defined as the placement of an endotracheal tube (ETT) prior to the induction of general anesthesia. Canadian and American guidelines acknowledge awake intubation as an option for management of the patient with an anticipated difficult airway. ${ }^{1,2}$ Awake intubation can provide an extra margin of safety by allowing the patient to maintain gas exchange, airway patency, and protection against aspiration during the procedure. Besides anticipated difficulty with tracheal intubation itself, a decision to proceed with awake intubation often relates to concomitant predictors of difficulty with bag and mask ventilation, use of a supraglottic device (SGD), or obtaining an emergency surgical airway. ${ }^{3}$ The presence of a full stomach, likely intolerance of apnea, or the absence of skilled assistance may also impact the decision. ${ }^{1}$

Successful and well-tolerated awake tracheal intubation requires a cooperative patient and excellent local anesthesia of the oropharynx, larynx, and trachea. The procedure can be facilitated by a judicious degree of systemic sedation. Although the flexible bronchoscope has traditionally been the most frequently used device to facilitate awake intubation, rigid video laryngoscopy (VL) has recently been described to facilitate awake intubation with comparable success. ${ }^{4-6}$

The well-performed awake intubation is a complex interaction of appropriate case selection, good patient preparation, and technical expertise in performing the procedure. It is a skill that should be acquired and maintained by all anesthesiologists. Nevertheless, as the need for awake intubation is relatively infrequent, few opportunities exist to acquire skills and maintain competence. This could be problematic, as a lack of confidence in performing awake intubation when significant difficulty is predicted could potentially lead to a less safe decision to induce general anesthesia before securing the airway. This tendency might be compounded by an overreliance on the efficacy of VL in addressing anatomic predictors of difficult direct laryngoscopy (DL).

Little information exists on how frequently awake tracheal intubation is used or whether its incidence is changing over time. Many clinicians have the impression that they are performing fewer awake intubations than in years past. A recently published analysis of 317,509 cases performed under general anesthesia at a hospital in the United States documented decreasing use of "fibreoptic intubation" over 12 years ending in February 2013, mirrored by an increase in the use of VL. ${ }^{7}$ Nevertheless, it was unclear from that report whether the use of fibreoptic intubation related only to awake intubation or included its use after the induction of general anesthesia. When directors of anesthesia residency training programs and 
continuing education officers are establishing optimal training regimens and professional development offerings, it would be useful for them to know how often awake tracheal intubation occurs and whether its incidence might be changing.

The primary purpose of this study was to determine the annual incidence of awake tracheal intubation and whether it had changed over the period 2002-2013. The null hypothesis was that the incidence of awake tracheal intubation had not changed significantly over this time period. As a secondary outcome, we determined how frequently alternatives to DL (such as VL) were used in each of the studied years to facilitate tracheal intubation after the induction of general anesthesia. Furthermore, we determined the success rate as well the incidence and type of reported complications for the identified attempted awake intubations.

\section{Methods}

This was a retrospective database review involving the Anesthesia Information Management System (AIMS) used in our operating rooms. The study was approved in January 2014 by the Research Ethics Board at the Capital District Health Authority in Halifax, NS. The requirement for individual patient consent to access personal health information was waived. The study included data from cases performed at the QEII Health Sciences Centre (an adult tertiary care institution performing most surgeries apart from obstetric and non-oncologic gynecologic procedures) from January 1, 2002 to December 31, 2013. An AIMS was in use for the entire time period, Saturn Information System from January 2002 to September 2010 and Innovian ${ }^{\circledR}$ Anesthesia from September 2010 to December 2013 (both Draeger Medical Inc., Telford, PA, USA).

The AIMS was electronically searched for all cases performed under general anesthesia. Of these, only cases involving transoral or transnasal tracheal intubation were further assessed - those performed with face mask ventilation, an SGD, or awake tracheostomy were excluded from analysis. To identify cases of awake tracheal intubation, Excel (Microsoft Corporation, Redmond, WA, USA) spreadsheets of the general endotracheal anesthesia (GETA) cases retrieved from the AIMS records were downloaded and separated into calendar years. After assessment of the total number of cases performed under GETA, each year was searched in all fields using the Excel "Find" function for the following key words or terms: awake intubation, awake fibreoptic, awake fiberoptic, awake fiber optic, awake bronchoscopic, awake, aware, tracheal intubation, fibre-optic, topical, tetracaine, SLN, superior laryngeal, gargle, paste, ointment, ungt, AFI, AFO, FB, FOB, FOI, pledg[ets], piriform, Kraus[e][forceps], Jackson [forceps], DeVil[biss], visc[ous], hurric[aine], atomi[zer], nebuli[zer], aerosol, transtrach[eal], fiberoptic, fibreoptic, bronchoscopic, EMLA. Lidocaine and Xylocaine were excluded as search terms due to their frequent recorded use for indications other than awake intubation. All retrieved entries were then manually assessed to confirm whether awake intubation had indeed been attempted. Awake intubation cases were pasted to a new spreadsheet for each studied year in order of date performed.

Data on each year's awake intubation spreadsheet were then examined to confirm the absence of duplicate entries for the same case by comparing unique numeric patient and case identifiers, surgery date, and surgery start times. The text for each retained entry was then re-reviewed in its entirety to determine the ultimate success of an attempted awake intubation, number of attempts, and nature of any recorded complications. For all identified cases of awake intubation, patient demographic information was retrieved from the same spreadsheet, including age, sex, and surgical procedure.

A second search of the initially retrieved AIMS GETA records was performed for each year to assess use of VL and non-VL alternatives to DL after induction of general anesthesia. Video laryngoscopes in use during some or all of the studied time period included the GlideScope ${ }^{\circledR}$ (Verathon Inc., Bothell, WA, USA), the Storz C-MAC ${ }^{\circledR}$ with Macintosh and D-Blades (Karl Storz Endoscopy America Inc., El Segundo, CA, USA), McGRATH ${ }^{\circledR}$ Series 5 (Aircraft Medical Ltd., Edinburgh, UK), Pentax-AWS ${ }^{\circledR}$ (Hoya Service Corp., Tokyo, Japan), and King Vision video laryngoscope (Ambu Inc., Glen Burnie, MD, USA). Non-VL alternatives included the Trachlight ${ }^{\mathrm{TM}}$ lighted stylet (Laerdal, Wappingers Falls, NY, USA - product discontinued 2009), Clarus Medical's Shikani, Levitan, and Video system viewing stylets (Clarus Medical, Minneapolis, MN, USA), the Bullard ${ }^{\mathrm{TM}}$ laryngoscope and the LMA-Fastrach ${ }^{\text {TM }}$ (Teleflex, Research Triangle Park, NC, USA). Brand and generic terms for these devices were searched for frequency of use. During this data extraction, no distinction was made between use of a device for an actual difficult intubation situation or for skills maintenance or teaching purposes. Use of flexible bronchoscopy in the induced patient was not assessed during this search component due to its overlapping roles in tracheal intubation, in positioning a double-lumen tube or bronchial blocker, and in both anesthesia- and surgicalrelated diagnostics.

Lastly, we studied a convenience sample of three years (2011-2013) to obtain information on how often individual attending anesthesiologists had performed an awake 
intubation. Anesthesiologists were included only if they had worked clinically for at least a full-time equivalent of 0.6 for all three years. Their individual rates of awake intubation were determined.

Changes in awake intubation and VL incidence over time were analyzed by examining their rates of use in sixmonth time intervals using linear regression analysis with time intervals as the independent variables. Slope estimates (representing the incidence-year ${ }^{-1}$ ), $P$ values, and the respective confidence intervals are reported for model results. Descriptive statistics (mean or median

Table 1 Details of surgical procedures of 1,554 patients undergoing awake tracheal intubation

\begin{tabular}{lll}
\hline Procedure & $(n=1,554)$ & Percent \\
\hline Otorhinolaryngology & 311 & $20 \%$ \\
Spine: cervical & 235 & $15 \%$ \\
General surgery & 228 & $15 \%$ \\
Orthopedics (non-spine) & 183 & $12 \%$ \\
Thoracic & 103 & $7 \%$ \\
Urology/gynecology & 97 & $6 \%$ \\
Oral-maxillofacial & 93 & $6 \%$ \\
Spine: thoracic/lumbar & 74 & $5 \%$ \\
Cardiac/vascular & 67 & $4 \%$ \\
Plastic surgery & 66 & $4 \%$ \\
Inflammatory head and neck (operative & 55 & $3 \%$ \\
$\quad$ or non-operative) & & \\
Neurosurgery (intracranial) & 42 & $3 \%$ \\
\hline
\end{tabular}

[interquartile range]) are presented for observations on patient age, staff awake intubation rates, and staff experience. Data were analyzed using R 3.1.1 statistical software (R Foundation for Statistical Computing, Vienna, Austria). ${ }^{8}$

\section{Results}

From January 1, 2002 to December 31, 2013, 205,623 cases were performed under general anesthesia. Of these, 59,371 cases $(29 \%)$ were performed with an SGD, face mask ventilation, or awake tracheostomy. Oral or nasal tracheal intubation occurred in the remaining 146,252 (71\%), and awake tracheal intubation was performed in $1,554(1.06 \%)$ of these cases. Five hundred twenty (33.5\%) of these patients were female and 1,034 (66.5\%) were male. The mean (interquartile range [IQR]) age was 55 [45-66] yr. The youngest patient was $16 \mathrm{yr}$ old and the oldest patient was $97 \mathrm{yr}$ old. Details of the patients' surgical procedures appear in Table 1. Eighteen cases retrieved using the keyword search parameters could not be confirmed as awake intubations during the manual review; consequently, they were excluded from awake group analysis but retained in the denominator totals.

The $1.06 \%$ overall incidence of awake intubation ranged from $0.92-1.32 \%$ annually. Table 2 outlines the incidence details in six-month time intervals. The incidence of awake intubation did not change significantly over this time

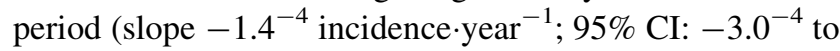
$\left.3.0^{-5} ; P=0.102\right)$.

Table 2 Incidence and success rates of awake tracheal intubation

\begin{tabular}{|c|c|c|c|c|c|c|c|c|c|c|c|c|c|c|}
\hline $\begin{array}{l}\text { 6-month } \\
\text { intervals }\end{array}$ & $\begin{array}{l}2002 \\
\text { Jan-Jun }\end{array}$ & $\begin{array}{l}2002 \\
\text { Jul-Dec }\end{array}$ & $\begin{array}{l}2003 \\
\text { Jan-Jun }\end{array}$ & $\begin{array}{l}2003 \\
\text { Jul-Dec }\end{array}$ & $\begin{array}{l}2004 \\
\text { Jan-Jun }\end{array}$ & $\begin{array}{l}2004 \\
\text { Jul-Dec }\end{array}$ & $\begin{array}{l}2005 \\
\text { Jan-Jun }\end{array}$ & $\begin{array}{ll}2005 \\
\text { Jul-De }\end{array}$ & & $\begin{array}{l}2006 \\
\text { Jan-Jun }\end{array}$ & $\begin{array}{ll}2006 & 2 \\
\text { Jul-Dec } & \mathrm{J}\end{array}$ & $\begin{array}{l}2007 \\
\text { Jan-Jun }\end{array}$ & $\begin{array}{l}2007 \\
\text { Jul-Dec }\end{array}$ & $\begin{array}{l}2008 \\
\text { Jan-Jun }\end{array}$ \\
\hline $\begin{array}{l}\text { Awake } \\
\text { intubations }\end{array}$ & 55 & 60 & 70 & 42 & 67 & 59 & 81 & 65 & & 63 & 54 & 64 & 66 & 83 \\
\hline $\begin{array}{l}\text { Total intubated } \\
\text { GA cases }\end{array}$ & 5,168 & 5,286 & 5,611 & 5,223 & 6,134 & 5,222 & 5,584 & 5,477 & & 5,372 & 5,130 & 6,101 & 6,375 & 7,190 \\
\hline \multicolumn{2}{|c|}{ 6-month intervals } & $\begin{array}{l}2008 \\
\text { Jul-Dec }\end{array}$ & $\begin{array}{l}2009 \\
\text { Jan-Jun }\end{array}$ & $\begin{array}{l}2009 \\
\text { Jul-Dec }\end{array}$ & $\begin{array}{l}2010 \\
\text { Jan-Jun }\end{array}$ & $\begin{array}{l}2010 \\
\text { Jul-Dec }\end{array}$ & $\begin{array}{l}2011 \\
\text { Jan-Jun }\end{array}$ & $\begin{array}{ll} & 2011 \\
n & \text { Jul-De }\end{array}$ & & $\begin{array}{l}2012 \\
\text { Jan-Jun }\end{array}$ & $\begin{array}{l}2012 \\
\text { Jul-Dec }\end{array}$ & $\begin{array}{l}2013 \\
\text { Jan-Jun }\end{array}$ & $\begin{array}{l}2013 \\
\text { Jul-Dec }\end{array}$ & Totals \\
\hline \multicolumn{2}{|c|}{ Awake intubations } & 63 & 68 & 79 & 60 & 67 & 68 & 69 & & 56 & 71 & 59 & 65 & 1,554 \\
\hline \multicolumn{2}{|c|}{ Total intubated GA cases } & 6,815 & 7,027 & 7,162 & 6,666 & 6,186 & 6,209 & 5,898 & & 6,672 & 6,203 & 7,111 & 6,430 & 146,252 \\
\hline \multicolumn{2}{|l|}{ Annual intervals } & 2002 & 2003 & 2004 & 2005 & 2006 & 2007 & 2008 & 2009 & 2010 & 2011 & 2012 & 2013 & Totals \\
\hline \multicolumn{2}{|c|}{ Awake intubation rate, $\%$} & 1.10 & 1.03 & 1.11 & 1.32 & 1.11 & 1.04 & 1.04 & 1.04 & 0.99 & 1.13 & 0.99 & 0.92 & 1.06 \\
\hline \multicolumn{2}{|c|}{ Failures } & 2 & 3 & 2 & 3 & 4 & 3 & 3 & 3 & 1 & 2 & 1 & 4 & 31 \\
\hline \multicolumn{2}{|c|}{ Overall success rate } & 98.3 & 97.3 & 98.4 & 97.9 & 96.6 & 97.7 & 97.9 & 98.0 & 99.2 & 98.5 & 99.2 & 96.8 & 98.0 \\
\hline \multicolumn{2}{|c|}{ First attempt success rate } & 93.8 & 95.4 & 96.8 & 95.8 & 93.8 & 98.4 & 95.8 & 93.8 & 90.5 & 91.9 & 91.3 & 89.2 & 93.9 \\
\hline
\end{tabular}

GA = general anesthesia; Jan = January; Jun = June; Jul = July; Dec = December 
Attempted awake intubation failed in $31(2 \%)$ of the 1,554 cases. The causes of failure and subsequent disposition of these cases appear in Fig. 1. The one case involving complete loss of airway patency ("can't intubate, can't ventilate") occurred during application of topical airway anesthesia in a patient with a submandibular abscess. In this case, an emergency surgical airway was successfully performed. No cases were cancelled or deferred following failed awake intubation.

A flexible bronchoscope was used to facilitate all but 12 of the 1,554 awake intubations (99.2\%) in this series. For the GETA cases intubated after induction, reported uses of VL and other alternatives to DL for the study period appear in Table 3 and are presented graphically in Fig. 2. There was a significant increase in the use of VL

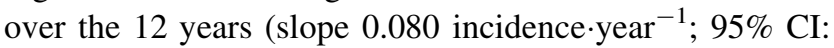
0.076 to $0.086 ; P<0.001$ ), most pronounced from 2009 onwards.

In the convenience sample (2011-2013) that assessed how often each of 49 individual anesthesiologists performed awake tracheal intubation, the median [IQR] rate of awake intubation was 0.8 [0.4-1.3] per 100 patients undergoing GETA and varied from a low of zero to a high of 3.4 per 100 patients undergoing GETA (Fig. 3). As our hospital is a teaching institution, the attending anesthesiologists in this analysis may have performed the awake intubation themselves or they may have acted in a supervisory role for a resident. The attending anesthesiologists' median [IQR] years of experience at the institution was 10.1 [6.1-17.1] yr.

Complications during successful awake intubation were self-reported in $239(15.7 \%)$ of the 1,554 cases (Table 4).

\section{Discussion}

There was no significant change in the incidence of awake tracheal intubation from 2002-2013 despite a significant increase in the use of $\mathrm{VL}$ for tracheal intubation after induction of general anesthesia, most prevalent from approximately 2009 onwards.

The relatively unchanged incidence of awake tracheal intubation may relate to the many alternatives to direct laryngoscopy (e.g., the Trachlight, LMA-Fastrach, Bullard laryngoscope, and flexible bronchoscope) that were widely available predating the introduction of VL. Thus, while an effective airway adjunct, ${ }^{9}$ the video laryngoscope may not have significantly impacted how often awake tracheal intubation is performed. Moreover, the decision to perform awake intubation also incorporates factors such as anticipated difficult bag and mask ventilation, a full stomach, predicted intolerance of apnea, or a lack of expert help. ${ }^{1}$ None these latter factors would be affected by VL, which might further explain the steady incidence of awake intubation over time. Even if the need for awake intubation had been diminished by more frequent use of $\mathrm{VL}$, it is also conceivable that such a decrease could have been masked by a concomitant rise in awake intubation for an increasing population of obese patients ${ }^{10}$ in whom a higher incidence of anticipated difficult airway management might be expected. ${ }^{11-20}$

While the overall incidence of awake tracheal intubation was $1.06 \%$ of GETA cases, there was substantial variability in the rate (0-3.4 per 100 GETA cases) at which individual attending staff performed the procedure. These results were not controlled for subspecialty practice (e.g.,

Fig. 1 Results and disposition of successful and failed attempted awake tracheal intubation. IV = intravenous; $\mathrm{GA}=$ general anesthesia; trach $=$ tracheostomy

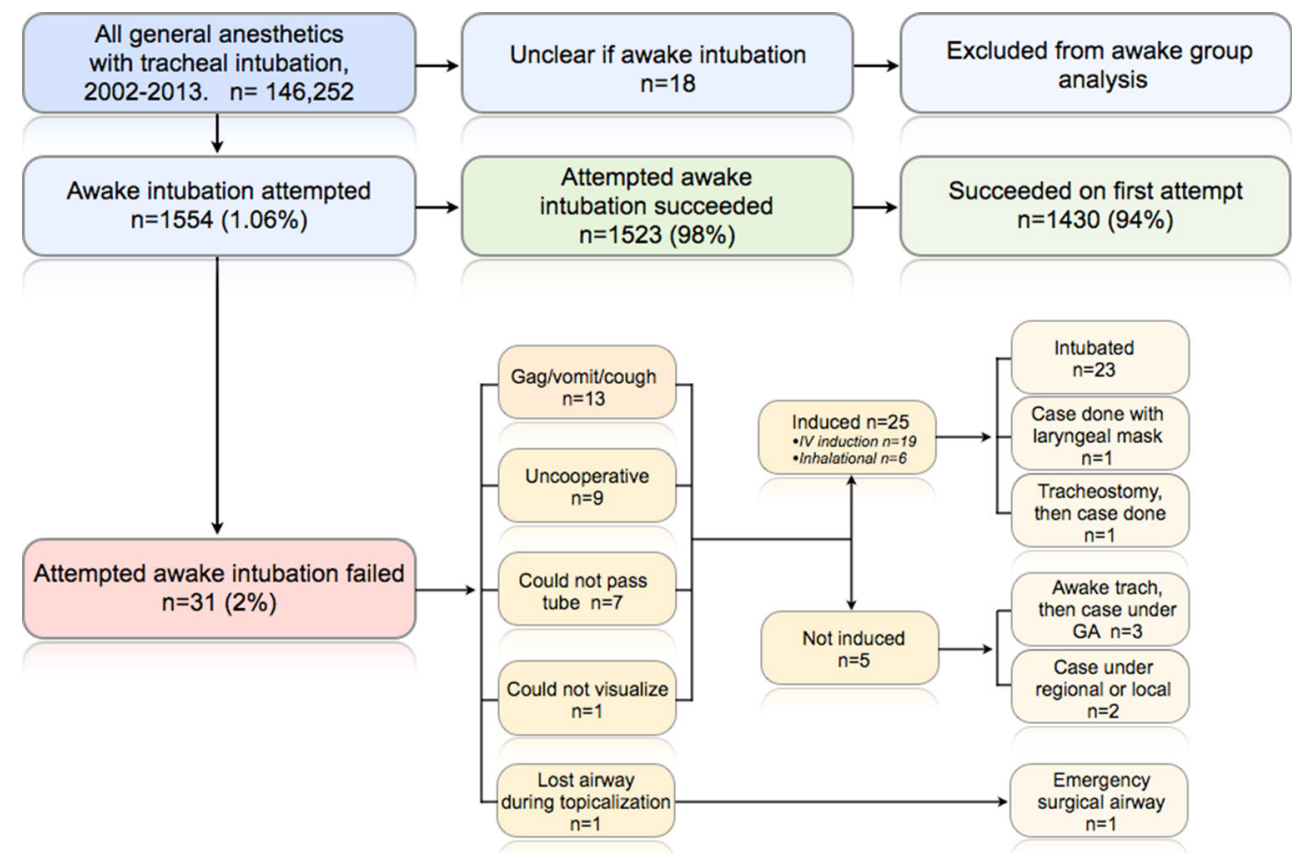




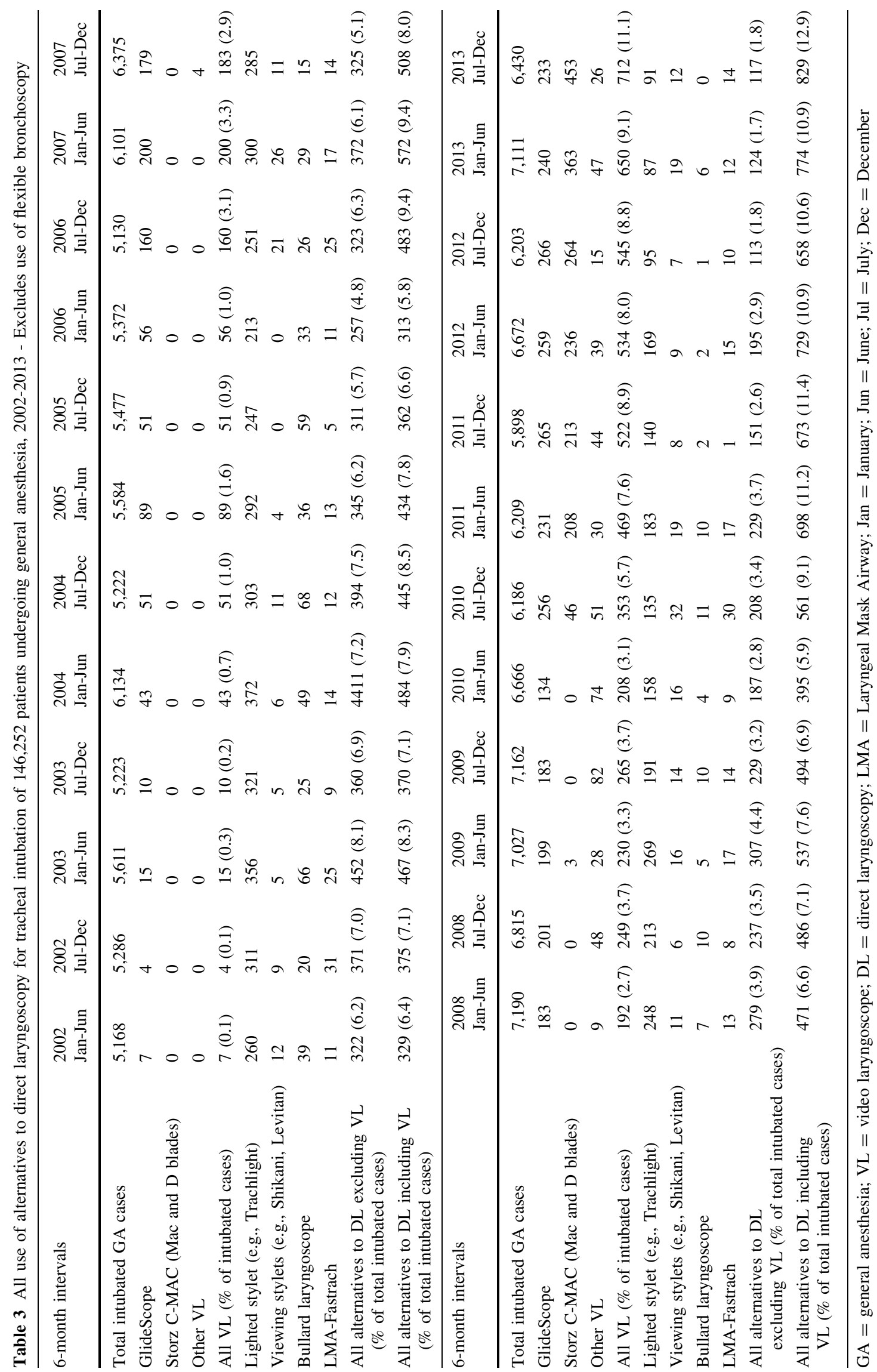


Fig. 2 Use of alternatives to direct laryngoscopy after induction of general anesthesia from 2002-2013. DL = direct laryngoscopy; $\mathrm{VL}=$ video laryngoscopy; LW = lighted stylet; ILMA = LMA-Fastrach; $\mathrm{BL}=$ Bullard laryngoscope; $\mathrm{VS}=$ viewing stylet

Fig. 3 Graphic representation of the rate of awake intubation per 100 general anesthesia cases requiring tracheal intubation for each of 49 attending staff anesthesiologists over three years
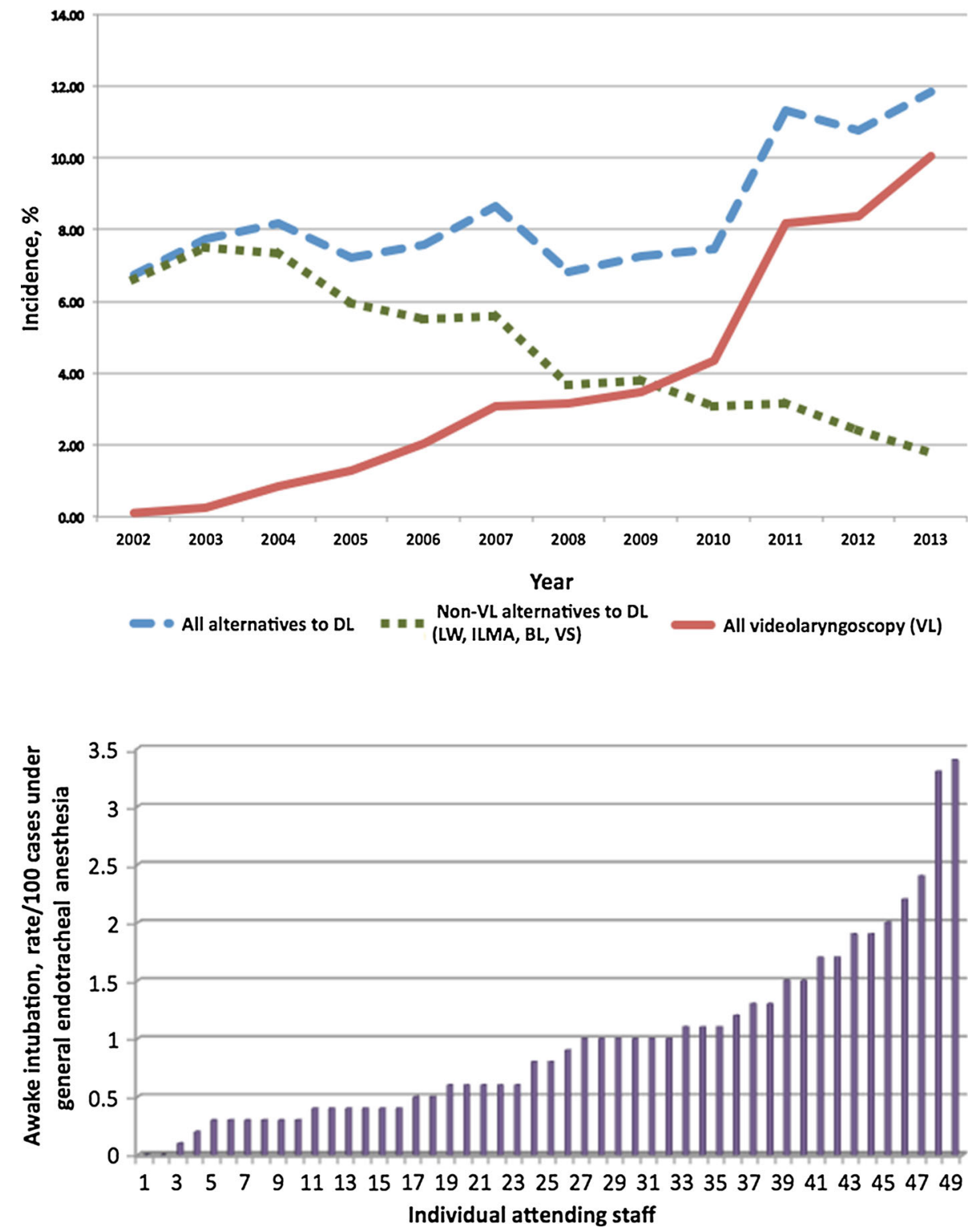

Table 4 Complications encountered during ultimately successful awake tracheal intubation

\begin{tabular}{lrr}
\hline Complication & Number $(n=239)$ & Percent \\
\hline$>1$ attempt, cause not specified & 64 & $26.8 \%$ \\
Cough or gag during intubation & 54 & $22.6 \%$ \\
Hang-up on larynx caused difficulty with tube passage but no change in tube size or type undertaken & 42 & 29 \\
Required change to smaller or Parker tube & 16 & $17.6 \%$ \\
Blood or secretions caused difficulty & 12 & $7.1 \%$ \\
Airway compromise occurred with application of local anesthetic & $5.7 \%$ \\
Patient uncooperative & $5.0 \%$ \\
Cuff leak apparent after intubation & 5 & $2.9 \%$ \\
Change of route required (nasal to oral or vice versa) & $4.1 \%$ \\
Patient excessively sedated & $2.1 \%$ \\
Inadvertent immediate extubation & $1.7 \%$ \\
\hline
\end{tabular}


anesthesiologists performing mainly regional vs neuroanesthesia), although anecdotally, the four individuals with the two lowest and the two highest rates of awake intubation had similar practice profiles (data not shown). This suggests at least some variability among staff in their personal thresholds for performing awake tracheal intubation.

Our findings are consistent with some of those reported recently in a study by Wanderer et al. ${ }^{7}$ In their large ( $n=317,509$ ) database review of cases conducted under general anesthesia using either an ETT or SGD during March 2001 to February 2013, a significant increase in the use of VL was reported beginning around 2008. A continuous decline in the use of the flexible bronchoscope was apparent during their study period, although no statistical analysis was reported for their observation. In addition, the report made no distinction between use of the device for awake tracheal intubation or for intubation after the induction of general anesthesia.

As our institution is a typical Canadian tertiary care centre with most types of surgery represented, we have no reason to suspect that the rate of awake intubation was any different from that at similar institutions. Nonetheless, we acknowledge that institutional preferences exist for certain practices or procedures. On that basis, even with comparable surgical populations, our incidence of awake tracheal intubation could differ from that occurring in other tertiary care hospitals. Our use of non-VL alternatives to DL (e.g., lighted stylet, LMA-Fastrach, Bullard laryngoscope, and visual stylets) decreased over the examined time period. We could not identify published literature with which to compare this finding. Although decreasing, lighted stylet use was significant at our institution throughout the time period.

An awake tracheal intubation was performed on more males than females by a ratio of $2: 1$. This finding corresponds with those in previous large-scale studies, i.e., males experience a higher incidence of difficult face mask ventilation and/or tracheal intubation than females. $^{21-24}$ It is also not unexpected that otolaryngology and cervical spine procedures were the most highly represented for awake intubation. That general surgery occurred next most commonly might be explained in some instances by full stomach concerns coinciding with predictors of difficult tracheal intubation.

The $2 \%$ failure rate of attempted awake intubation was comparable with rates of $1.2-1.8 \%$ published previously in the context of clinical trials. ${ }^{25,26}$ Sixty-five percent of awake intubation failures and $52 \%$ of recorded complications in this study related to either difficulty with ETT passage through the larynx or suboptimal topical airway anesthesia. Both of these complications could potentially be prevented, e.g., with the primary use of a smaller or Parker ETT (Parker Medical, Englewood, CO, USA $)^{27}$ over an adult-sized bronchoscope or with more effective application of topical airway anesthesia, respectively. It is also worth mentioning that $5 \%$ of the self-reported complications related to partial or complete compromise of airway patency simply with application of topical airway anesthesia. This has been previously described $^{28-33}$ but is an underappreciated phenomenon that underscores the need for an alternative plan even with the alleged safety margin provided by awake intubation.

Published guidelines continue to recommend awake intubation as an option for the patient with anticipated difficult airway management. ${ }^{1,2}$ Knowledge of the incidence of awake tracheal intubation may help provide benchmark data for residency programs and continuing education officers in designing airway education curriculum.

There were some limitations to our study. Although we have no reason to think that our surgical case mix or patient population differs significantly from other tertiary care centres (i.e., our results should be generalizable to other similar centres), they may not be applicable to nonteaching or community-type practices. Furthermore, the findings may not necessarily be applicable to out-ofoperating room environments such as emergency departments or critical care units. As a retrospective study, some results may have been prone to imprecision and underreporting, especially self-reported factors such as the need for multiple or prolonged attempts at awake tracheal intubation or other complications encountered during the procedure.

In conclusion, during 2002-2013 at our tertiary care institution, $1.06 \%$ of patients undergoing general anesthesia with tracheal intubation underwent awake intubation. No significant change in the incidence of awake tracheal intubation was observed over the study time period. Awake tracheal intubation appears to have a high success rate. Variability in the use of awake intubation among staff could have implications for quality assurance surveillance and continuing professional development programs. In spite of the increasing use of VL, it appears that awake tracheal intubation retains an important and consistent role in the management of the difficult airway.

Acknowledgement Work supported by the Department of Anesthesia, Dalhousie University.

Conflicts of interest None declared.

\section{References}

1. Law JA, Broemling N, Cooper RM, et al. The difficult airway with recommendations for management-part 2-the anticipated difficult airway. Can J Anesth 2013; 60: 1119-38. 
2. Apfelbaum JL, Hagberg CA, Caplan RA, et al. Practice guidelines for management of the difficult airway: an updated report by the American Society of Anesthesiologists Task Force on Management of the Difficult Airway. Anesthesiology 2013; 118: 251-70.

3. Murphy M, Hung O, Launcelott G, Law JA, Morris I. Predicting the difficult laryngoscopic intubation: are we on the right track? Can J Anesth 2005; 52: 231-5.

4. Rosenstock CV, Thogersen B, Afshari A, Christensen AL, Eriksen $C$, Gatke MR. Awake fiberoptic or awake video laryngoscopic tracheal intubation in patients with anticipated difficult airway management: a randomized clinical trial. Anesthesiology 2012; 116: 1210-6.

5. Abdellatif AA, Ali MA. GlideScope videolaryngoscope versus flexible fiberoptic bronchoscope for awake intubation of morbidly obese patient with predicted difficult intubation. Middle East $\mathbf{J}$ Anaesthesiol 2014; 22: 385-92.

6. Wahba SS, Tammam TF, Saeed AM. Comparative study of awake endotracheal intubation with Glidescope video laryngoscope versus flexible fiber optic bronchoscope in patients with traumatic cervical spine injury. Egyptian Journal of Anaesthesia 2012; 28 : 257-60.

7. Wanderer JP, Ehrenfeld JM, Sandberg WS, Epstein RH. The changing scope of difficult airway management. Can J Anesth 2013; 60: 1022-4.

8. R Development Core Team. R: A Language and Environment for Statistical Computing. Vienna, Austria: R Foundation for Statistical Computing; 2011 Available from URL: http://www. R-project.org/ (accessed February 2015).

9. Griesdale DE, Liu D, McKinney J, Choi PT. Glidescope(R) videolaryngoscopy versus direct laryngoscopy for endotracheal intubation: a systematic review and meta-analysis. Can J Anesth 2012; 59: 41-52.

10. Ogden CL, Carroll MD, Kit BK, Flegal KM. Prevalence of obesity in the United States, 2009-2010; Centers for Disease Control and Prevention, number 82, 2012. Available from URL: http://www.cdc.gov/nchs/data/databriefs/db82.htm (accessed February 2015).

11. Kheterpal $S$, Han $R$, Tremper $K K$, et al. Incidence and predictors of difficult and impossible mask ventilation. Anesthesiology 2006; 105: 885-91.

12. Langeron $O$, Masso $E$, Huraux $C$, et al. Prediction of difficult mask ventilation. Anesthesiology 2000; 92: 1229-36.

13. Yildiz TS, Solak M, Toker $K$. The incidence and risk factors of difficult mask ventilation. J Anesth 2005; 19: 7-11.

14. Gautam P, Gaul TK, Luthra N. Prediction of difficult mask ventilation. Eur J Anaesthesiol 2005; 22: 638-40.

15. Ramachandran SK, Mathis MR, Tremper KK, Shanks AM, Kheterpal $S$. Predictors and clinical outcomes from failed Laryngeal Mask Airway Unique ${ }^{\mathrm{TM}}$ : a study of 15,795 patients. Anesthesiology 2012; 116: 1217-26.

16. Brodsky JB, Lemmens HJ, Brock-Utne JG, Vierra M, Saidman $L J$. Morbid obesity and tracheal intubation. Anesth Analg 2002; 94: 732-6.

17. Hekiert AM, Mick R, Mirza N. Prediction of difficult laryngoscopy: does obesity play a role? Ann Otol Rhinol Laryngol 2007; 116: 799-804.
18. Lundstrom LH, Moller AM, Rosenstock C, Astrup G, Wetterslev J. High body mass index is a weak predictor for difficult and failed tracheal intubation: a cohort study of 91,332 consecutive patients scheduled for direct laryngoscopy registered in the Danish Anesthesia Database. Anesthesiology 2009; 110: 266-74.

19. Gonzalez H, Minville V, Delanoue K, Mazerolles M, Concina D, Fourcade $O$. The importance of increased neck circumference to intubation difficulties in obese patients. Anesth Analg 2008; 106: 1132-6.

20. Juvin P, Lavaut E, Dupont $H$, et al. Difficult tracheal intubation is more common in obese than in lean patients. Anesth Analg 2003; 97: 595-600.

21. Amathieu R, Combes $X$, Abdi W, et al. An algorithm for difficult airway management, modified for modern optical devices (Airtraq laryngoscope; LMA CTrach ${ }^{\mathrm{TM}}$ ): a 2-year prospective validation in patients for elective abdominal, gynecologic, and thyroid surgery. Anesthesiology 2011; 114: 25-33.

22. Combes $X$, Le Roux B, Suen P, et al. Unanticipated difficult airway in anesthetized patients: prospective validation of a management algorithm. Anesthesiology 2004; 100: 1146-50.

23. Kheterpal S, Martin L, Shanks AM, Tremper KK. Prediction and outcomes of impossible mask ventilation: a review of 50,000 anesthetics. Anesthesiology 2009; 110: 891-7.

24. Kheterpal $S$, Healy D, Aziz MF, et al. Incidence, predictors, and outcome of difficult mask ventilation combined with difficult laryngoscopy: a report from the multicenter perioperative outcomes group. Anesthesiology 2013; 119: 1360-9.

25. Ovassapian A, Yelich SJ, Dykes MH, Brunner EE. Fiberoptic nasotracheal intubation-incidence and causes of failure. Anesth Analg 1983; 62: 692-5.

26. Heidegger T, Gerig HJ, Ulrich B, Schnider TW. Structure and process quality illustrated by fibreoptic intubation: analysis of 1612 cases. Anaesthesia 2003; 58: 734-9.

27. Jafari A, Gharaei B, Kamranmanesh MR, et al. Wire reinforced endotracheal tube compared with Parker Flex-Tip tube for oral fiberoptic intubation: a randomized clinical trial. Minerva Anestesiol 2014; 80: 324-9.

28. McGuire G, el-Beheiry H. Complete upper airway obstruction during awake fibreoptic intubation in patients with unstable cervical spine fractures. Can J Anesth 1999; 46: 176-8.

29. Ho AM, Chung DC, To EW, Karmakar MK. Total airway obstruction during local anesthesia in a non-sedated patient with a compromised airway. Can J Anesth 2004; 51: 838-41.

30. Ho AM, Chung DC, Karmakar MK, Gomersall CD, Peng Z, Tay $B A$. Dynamic airflow limitation after topical anaesthesia of the upper airway. Anaesth Intensive Care 2006; 34: 211-5.

31. Shaw IC, Welchew EA, Harrison BJ, Michael S. Complete airway obstruction during awake fibreoptic intubation. Anaesthesia 1997; 52: 582-5.

32. Liistro G, Stanescu DC, Veriter C, Rodenstein DO, D'Odemont $J P$. Upper airway anesthesia induces airflow limitation in awake humans. Am Rev Respir Dis 1992; 146: 581-5.

33. Mason RA, Fielder $C P$. The obstructed airway in head and neck surgery. Anaesthesia 1999; 54: 625-8. 